\title{
Exploring the Reception of the Tele-Based Music Program in People with Parkinson's Disease During the Period of the Movement Control Order Due to The Covid-19 Pandemic
}

Mei Foong Ang, Indra Selvarajah

To Link this Article: http://dx.doi.org/10.6007/IJARBSS/v11-i11/11647

DOI:10.6007/IJARBSS/v11-i11/11647

Received: 17 September 2021, Revised: 22 October 2021, Accepted: 18 November 2021

Published Online: 26 November 2021

In-Text Citation: (Ang \& Selvarajah, 2021)

To Cite this Article: Ang, M. F., \& Selvarajah, I. (2021). Exploring the Reception of the Tele-Based Music Program in People with Parkinson's Disease During the Period of the Movement Control Order Due to The Covid-19 Pandemic. International Journal of Academic Research in Business and Social Sciences, 11(11), $1580-1598$.

Copyright: (c) 2021 The Author(s)

Published by Human Resource Management Academic Research Society (www.hrmars.com)

This article is published under the Creative Commons Attribution (CC BY 4.0) license. Anyone may reproduce, distribute, translate and create derivative works of this article (for both commercial and non0-commercial purposes), subject to full attribution to the original publication and authors. The full terms of this license may be seen at: http://creativecommons.org/licences/by/4.0/legalcode

Vol. 11, No. 11, 2021, Pg. 1580 - 1598

Full Terms \& Conditions of access and use can be found at http://hrmars.com/index.php/pages/detail/publication-ethics 


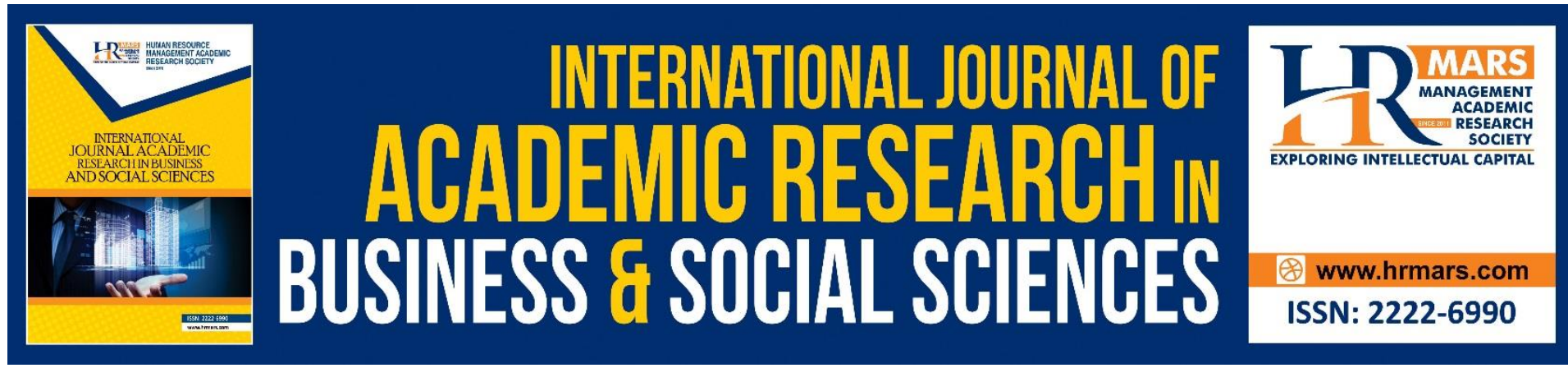

\title{
Exploring the Reception of the Tele-Based Music Program in People with Parkinson's Disease During the Period of The Movement Control Order Due to The Covid-19 Pandemic
}

\author{
Mei Foong Ang, Indra Selvarajah \\ Department of Music, Faculty of Human Ecology, Universiti Putra Malaysia, 43400 Serdang, \\ Selangor \\ Email: meifoong@upm.edu.my, indra@upm.edu.my
}

\begin{abstract}
One of the consequences of the Covid-19 pandemic was the country's lockdown with the new normal "social-distancing" being mandated. This might have worsened the management of some chronic diseases such as Parkinson's Disease (PD). PD is a chronic neurodegenerative disease in which the symptoms of the disease worsen over time. Apart from the prominent motor problems, studies also noted that the quality of life (QoL) of the People with Parkinson's Disease (PwP) deteriorates significantly with increasing disease severity. The impairment in the QoL often causes PwP to social withdrawal and social isolation, leading to higher possibilities for PwP to develop neuropsychiatric disorders such as anxiety and depression, as well as causing caregivers' distress. A tele-based music program was designed for the PwP aiming to encourage social engagement and to instil positive living. This paper reports the preliminary findings of the reception of a trial tele-based music program on psychosocial wellbeing in people with PwP.
\end{abstract}

Keywords: Parkinson's Disease, Psychosocial Wellbeing, Tele-based Music Program, COVID19, Quality of Life

\section{Introduction}

Parkinson's Disease (PD) is a chronic progressive degenerative neurological disorder that is caused by the reduction of dopamine in the brain (Lim et al., 2012; Schulz \& Grant, 2000). The disease is characterized clinically by motor problems such as tremor at rest, bradykinesia (slowness), cogwheel rigidity, and postural instability. The symptoms of the disease deteriorate over time and there is no cure for it thus far (Aarsland et al., 1999; Branchi et al., 2008; Jankovic, 2008; Meireles \& Massano, 2012; Rutten et al., 2014)

Prominent symptoms in PD are the motor problems. However, it also has a tendency to provoke mental health issues (Aarsland et al., 1999; Branchi et al., 2008; Jankovic, 2008; Meireles \& Massano, 2012; Rutten et al., 2014). It had also been reported that non-motor problems such as sleep disturbance, fatigue, sleep disorders and constipation could 
sometimes emerge before the motor problems (Lim et al., 2009). When the disease progresses, people diagnosed with Parkinson's Disease (PwP) also face psychological challenges such as anxiety and depression. These secondary comorbidities affect the PwPs mental health and impact on their quality of life (Aarsland et al., 1999; Chaudhuri et al., 2006; Hughes et al., 1992; Jankovic, 2008; Massano \& Bhatia, 2012; Meireles \& Massano, 2012; Politis et al., 2010)

PD affects almost $1-2 \%$ of people over the age of 60 , or $0.3 \%$ in the general population (Massano \& Bhatia, 2012). PD is the second most common neurodegenerative disease after Alzheimer's disease. It is also documented that men are more likely to have PD than women, with male-female ratio at 3:2 being recorded in most studies (Alves et al., 2008; de Lau \& Breteler, 2006). According to the crude prevalence rate of PD worldwide, it can be predicted that Malaysia will have approximately 8,490 new PD cases yearly, based on the population number of the national census 2010 from the Department of Statistics Malaysia.

In the meantime, based on the rising numbers of the population at all ages in Malaysia. It can be forecasted that the transition of the age structure is pushing towards an aging population in Malaysia. According to the 2010 Malaysia census, the median age of the Malaysian population increased from 23.6 years in 2000 to 26.2 years in 2010, while the population aged 65 and above also increased from $3.9 \%$ in 2000 to $5.1 \%$ in 2010 . Adding together with the rising prevalence of PD, there is a big possibility that a drastic increment of PD may cause serious issues to the health care system at the societal level and at the national level on the annual medical costs, public healthcare systems and infrastructures, especially when the cost of care escalates over the years (Boland \& Stacy, 2012; Pringsheim et al., 2014).

Even though PD is more common in the older people, but the onset of the disease can be as early as in the adolescent years (Lim et al., 2012; Massano \& Bhatia, 2012). The early onset of $\mathrm{PD}$ also requires a more strategic management plan when the disease develops further as the disease is known to have no cure and the symptoms will deteriorate over time. Hence, medical management is also largely focusing on improving the impact of the disease on the quality of life of the PwP (Calne et al., 2008; Schrag, 2006)

\section{Non-Motor Symptoms and Psychological Challenges in PD}

Despite the disease being generally diagnosed by the prominent motor problems, there is consensus in the literature that non-motor problems can occur before the motor problems (Chaudhuri et al., 2006; Lim et al., 2009; Massano \& Bhatia, 2012; Politis et al., 2010; Schrag, 2006; Schrag et al., 2000). However, some non-motor problems such as audio and visual hallucinations normally manifest in the advanced stage of some PwPs, are often recognized as side-effects of medication (Chaudhuri et al., 2006).

Among the non-motor problems, neuropsychiatric features such as anxiety and depression are the overt neuropsychiatric disorders among PwP (Branchi et al., 2008; Rutten et al., 2014). It was reported that $40-50 \%$ of PwP presented clinically relevant anxiety symptoms (Calne et al., 2008). A factor analysis study conducted by Rutten et al. (2014) concluded that autonomic failure affects anxiety. They also reported that the symptoms of anxiety and depression showed large overlaps. Anxiety may also be a psychological reaction to the stress of the illness or it may be related with the neurochemical changes of the disease. In general, anxiety 
disorder in PD can be categorized into three main categories: panic, phobic and a generalized anxiety disorder (Calne et al., 2008; Rutten et al., 2014).

The co-morbidity is consistent to another longitudinal study conducted by Wee et al. (2016) who reported a high association between anxiety and depression among PwP. However, the disclosure of anxiety can be present in the absence of depression and vice versa; The presence of anxiety is also associated with exacerbation of the motor problems. Meanwhile, motorsymptoms such as "wearing-off" can also trigger or worsen anxiety (Prediger et al., 2012; Rutten et al., 2014).

Depression, on the other hand, affects $40-50 \%$ of the PwP, and it had been estimated that minor depression occurred at 20-45.3\% among PwP, while major depression occurred at 2.7$53.6 \%$ among them. As reported by Dyduch and Zaluska (2014), the symptoms of depression may occur before, along, or after the manifestations of the motor symptoms. PwPs with predominant rigidity and bradykinesia are more likely to develop depression than PWP with tremor. However, the authors also argued that despite depression being a common neuropsychiatric problem among PwPs, there had been no reliable standard of treatments thus far (Chung et al., 2003). Depression is often emphasized as a major factor in determining the quality of life. However, despite its impact, there was very limited attention being paid to this matter, nor was it being treated in clinical practice (Chung et al., 2003; Dyduch \& Załuska, 2014; Rahman et al., 2008; Shulman et al., 2002).

Mental impairments and PD related neuropsychiatric disorders PD create huge impacts on quality of life in the PwP and they are important factors contributing to caregivers' distress (Aarsland et al., 1999). In a research conducted by Aarsland et al (1999) which studied the contributors or factors of PwP-caregivers' distress, it was concluded that the severity of the motor symptoms and the stage of the disease might not influence caregiver distress if the mental disturbances were excluded. It was also reported that depression in PD was a strong contributor to caregiver distress.

In addition to this, Chaudhuri et al (2006) further noted that sometimes non-motor symptoms could overpower the clinical picture of PD when the disease progressed and led to severe disability, shortened life expectancy and impaired quality of life (Branchi et al., 2008; Chaudhuri et al., 2006; Pont-Sunyer et al., 2015; Rahman et al., 2008). Non-motor problems co-exist with the motor dysfunction, and can be manifested intricately in many different ways. So it is an important factor to determine the quality of life which can modify the course of PD (Dyduch \& Załuska, 2014).

\section{Role of Music for Psychosocial Well-Being in People with Parkinson's Disease}

In recent years, extensive researches reported music based intervention can give significant positive effects on both physical health and mental well-being on the PwP (Vella-Burrows et al., 2012), including the improvements in emotional well-being related to the hormones released in the body (Beck et al., 2000; Grape et al., 2003; Juslin \& Sloboda, 2010), and enhancements in social well-being, for instance, the feeling of being included or the sense of being accepted in a societal setting (Clift et al., 2010; Clift \& Hancox, 2010). 
There are studies that explored the benefits of singing to alleviate emotional difficulties associated with PD. In a research done by Pacchetti et al. (2000), significant improvements in emotional well-being in the PwP were found. In their RCT single-blinded study, the research participants were measured for their emotional functions via "Happiness Measure", and for quality of life with the Parkinson's Disease Quality of Life (PD-Q39) questionnaire. Changes on the Happiness Measure confirmed a significant positive effect of music therapy on emotional functions ( $p<.0001)$, as well as improvements in activities of daily living and in the quality of life $(p<.0001)$. Pacchetti et al (2000) further explained that the improvements in emotions might be related to high levels of sensory stimulation of personal interaction (Pacchetti et al., 2000).

Another more recent study of an exploration of participants' experience in choral singing therapy (CST) in Auckland, New Zealand (Fogg-Rogers et al., 2015) revealed that choral singing helped PwP to self-manage some consequences of their conditions such as low mood, social isolation and communication difficulties.

Furthermore, there is extant research on PwP that indicates the existing gender differences in terms of how clinical symptoms affect the quality of life of PD patients and their abilities to perform activities of daily living, participate in social activities as well as access medical care. A recent study exploring the relationship among three Health Related Quality of Life (HrQoL) domains (physical-functioning, cognition, socioemotional) and sociodemographic variables in PwP during the Covid-19 pandemic, discovered that female PwPs proved to be a negative predictor for physical-functioning and socioemotional HrQoL, whereas male PwP mainly affected the HrQoL cognition domain (Ophey et al., 2018). Conversely, in another prospective study on a cohort of patients with idiopathic PD in Germany, female patients reported more problems in all dimensions of HrQoL, with the exception of one category which was self-care (Balzer-Geldsetzer et al., 2018). Another longitudinal study analysing the effect of PD onset on life satisfaction noted a marked reduction of life satisfaction among individuals in the second half of life in men, but not in women (Buczak-Stec et al., 2018). Collectively, these studies imply that gender differences have been consistently found in response to quality of life in people with Parkinson's Disease in the midst of the pandemic (Cerri et al., 2019).

\section{Music Therapy in Telehealth}

Technological advancement had contributed to music therapy practice. Since a decade ago, a variety of tele-based music interventions were used when clients requested tele-based music therapy services from far due to the lack of music therapists available at the clients' areas (Vaudreuil et al., 2020).

These prior studies have shown that telehealth care in music therapy can provide significant benefits to clients; for example, Baker \& Krout (2009) assessed the effectiveness of a telebased songwriting intervention on adolescents with Asperger's Syndrome and concluded that there were more instances of eye contact, laughter, longer duration of engagement and higher level of creativity from the clients after the telehealth intervention.

A case-study done by Lightstone et al (2015) reported that tele-based music intervention that involved musical improvisation was effective in treating a veteran who suffered from posttraumatic stress disorder (PTSD). Many of the veteran's symptoms improved, included his 
ability to tolerate, express himself, and avoid dissociation that was associated with various emotions.

Other tele-based music intervention programs include an inter-national program done by music therapy lecturers and students at the Berklee School of Music from the United States to the child-soldiers in Uganda where they included music therapy activities such as singing, dancing, call-and response drumming and improvised music (Vaudreuil et al., 2020); Another telehealth music therapy program was contracted in Southern California in 2013 when a veteran who was diagnosed with Traumatic Brain Injury (TBI) was unable to continue his inperson music therapy treatment, henceforth, a tele-based music therapy program was introduced 1 to 2 times weekly where he could continue to attend the series of music therapy sessions at the facility where he was put. The therapy sessions included a music-based relaxation activity, song-lyric analysis and discussion, active music making, singing, songwriting, recording and music production through internet. The outcome of the session showed decreased pain perception, anxiety, and depression level (Vaudreuil et al., 2020).

In response to the consequences of the Covid-19 pandemic, tele-based music intervention allowed the PwP to remain socially and musically connected through an online setting. Since 2015, the American Music Therapy Association (AMTA) has listed professional competencies that focused on "Electronic Music Technology" while establishing an online tele-based music therapy session.

However, tele-based music intervention is still relatively new compared to other telemedicine services as the earliest telemedicine can be traced back to the late 1950s at the Nebraska Psychiatric Institute and Norfolk State Hospital for psychiatric consultations (NCBI, 2012). While there is a growing need for innovative care, more evidence-based research findings can remedy the paucity of work in the area.

As the coronavirus (COVID-19) outbreak continues to impact peoples' daily lives worldwide, research also investigates how COVID-19 has impacted the PwPs. Many recent research noted significant increment in the problems that are related to the management of the disease that include worsening of motor symptoms, and the absence of appropriate expert advice (Prasad et al., 2020). Another recent study done in Cairo revealed that the COVID-19 pandemic lockdown has a negative impact on the PwPs' mental health, physical activity and health care, in which the study reported significant worsen depression, anxiety, and stress, as well a significant decline of physical activity during the lockdown due to the pandemic (Shalash et al., 2020). The availability of some easy-accessible telemedicine may help to alleviate these problems.

\section{Methodology}

\section{Participants}

Nineteen PwPs were included in this study on a voluntary basis. All participants were recruited at the occasion of a tele-based music program named the "Sing for Parkinson's". This program was in collaboration with the Malaysian Parkinson's Disease Association (MPDA). There was no restriction on age, gender, and the stage of the disease. 
Table 1. Demographic characteristics of the participants

\begin{tabular}{cccc}
\hline Variables & \multicolumn{3}{c}{$\mathbf{N}(\%)$} \\
\hline Age group & All & Gender (Male) & Gender (Female) \\
$41-50$ y/o & $1(5.3 \%)$ & $1(5.3 \%)$ & 0 \\
$51-60$ y/o & $1(5.3 \%)$ & $1(5.3 \%)$ & 0 \\
$61-70$ y/o & $8(42.1 \%)$ & $5(26.3 \%)$ & $3(15.7 \%)$ \\
$71-80$ y/o & $9(47.3 \%)$ & $5(26.3 \%)$ & $4(21.1 \%)$ \\
Unemployed & $18(94.7 \%)$ & 0 & $18(94.7 \%)$ \\
\hline
\end{tabular}

Table 1 shows the basic demographic details of the participants. There was a total of 19 participants who took part in this tele-based music program, with 12 males (63.2\%) and 7 females (36.8\%). Even though there was no restriction of age for participation, but from the basic demographic data, it was noted that the majority of the participants belonged to the age-group of 71-80 years old, which consisted of 9 person (47.37\%), followed by 8 person in the age-group of $61-70$ years old (42.11\%), 1 person in the age-group of $51-60(5.26 \%)$ and 1 person in the age group of 41-50 years old.

Eighteen out of the 19 participants were unemployed (94.7\%) whilst 1(5.3\%) were still working. The participants joined the tele-based music program from their respective homes from various parts of Malaysia, covering the areas below: Kuala Lumpur, Petaling Jaya, Seri Kembangan, Kota Kinabalu, Keningua, Sungai Petani, Port Kelang, Subang Jaya and Cheras. The covered districts included the Northern and Central regions in Peninsular Malaysia as well as East Malaysia on the island of Borneo.

\section{Methods and Procedures}

This was an exploratory study with the main objective to explore the reasons of the PwPs to participate in a tele-based music program and the participants' emotional reactions after the program to better understand the perception of a tele-based music program from the point of view of the clients themselves.

\section{Tele-Based Music Program}

A tele-based music program was introduced to the participants in this study, this music program consisted of two major sessions: (i) Vocal Coaching, and (ii) Active Singing, which were layered and embedded into the protocol.

This tele-based music program was designed based on the Western vocal pedagogy, and was conducted in group, it ran 2-hours weekly for two consecutive weeks. The first half-hour session was a vocal coaching session which focused on vocal warm-up and vocal techniques building through breathing exercises and vocal exercises, this is conducted with diaphragmatic breathing techniques through a series of structured breathing exercises. The difficulty of the breathing exercises was layered and graduated by prolonging the breathholding time and combining the breathing exercises with the vocalise exercises.

The following half-hour sessions were categorized as the active singing session, which focused on active group singing that required the participants to sing with mild body movements for half an hour, followed with another half-hour session to do songs and song texts enunciations, 
and the last half-hour session focused on recapitulations and repetitions of the music activities of the day.

\section{Procedures}

An exploratory quantitative method was used in this study. The participants were given 2hours tele-based music program in two consecutive weeks. At the end of the program, the participants were asked to fill up a Music Experience Rating Scale (MERS) based on their online musicking experience. The MERS is a self-administered questionnaire developed by the researchers.

MERS consisted of two main sections: The first section of the questionnaire intended to find out the reasons why the participants make a decision to join the online music program; the participants were asked to rank all the 12 statements by responding how true the statement was to them, the responses were noted in a 6-point Likert-scale, with 1=very untrue, $2=$ untrue, $3=$ somewhat untrue, $4=$ somewhat true, $5=$ true and $6=$ very true. The 12 statements were: (1) to tackle your speech or voice problems due to Parkinson's Disease; (2) for entertainment; (3) interest in music or singing itself; (4) to create atmosphere in social situations; (5) to enhance positive moods; (6) to forget about the present; (7) to relax and calm down; (8) to reduce feeling of loneliness; (9) to feel akin with others; (10) to gain control of sounds; (11) to learn new skills; and lastly (12) to strengthen self-esteem.

The second section intended to find out the participants' emotional reaction after they have followed through the musicking process. The participants were asked to respond to the questions, "How common is it that you feel a certain emotion in response to music?" A total of 22 emotional reactions were asked for, consisting of positive, mixed, and negative emotions. The positive emotional reactions included happy, enjoying, calm, interested, motivated, relaxed, hopeful, loving, uplifted and relieved; the mixed emotional reactions included nostalgic, longing, reminisces, proud, and honoured; the negative emotional reaction included tensed, disappointed, bored, jealous, afraid, anxious, and sad. The participants were asked to rank the frequency of when they felt a certain emotion and the responses were noted in a 4 -points Likert-scale, with $1=$ never, $2=$ seldom, $3=$ often, and 4 = always.

The MERS questionnaire was developed with a Google form available online, the participants were requested to rate their experiences after the end of the tele-based music program. At the end of the questionnaire, there was also an open-ended question that requested the participants to elaborate on their online tele-based music program experiences.

\section{Results and Findings}

Table 2 reports the details of the reasons which made the participants to take part in the telebased music program. A total of $13(68.4 \%)$ responses agreed that it was very true for the statement which stated the reason they joined the tele-based music program was to tackle their speech and voice problem, followed by 3 (15.8\%) who responded true; 2 (10.5\%) who responded somewhat true, and 1 (5.3\%) who responded very untrue. 
INTERNATIONAL JOURNAL OF ACADEMIC RESEARCH IN BUSINESS AND SOCIAL SCIENCES Vol. 11, No. 11, 2021, E-ISSN: 2222-6990 @ 2021 HRMARS

Table 2: Descriptive statistics of the Degree of Truth of the Reasons to Join the Tele-based Music Program

\begin{tabular}{|c|c|c|c|c|c|c|}
\hline \multirow[t]{2}{*}{ Variables } & \multicolumn{6}{|c|}{$\mathbf{N}(\%)$} \\
\hline & $\begin{array}{l}\text { very } \\
\text { untrue }\end{array}$ & untrue & $\begin{array}{l}\text { somewh } \\
\text { at untrue }\end{array}$ & $\begin{array}{l}\text { somewh } \\
\text { at true }\end{array}$ & true & very true \\
\hline $\begin{array}{l}\text { to tackle speech or } \\
\text { voice problems due } \\
\text { to Parkinson's } \\
\text { Disease }\end{array}$ & $1(5.3 \%)$ & - & - & $2(10.5 \%)$ & $3(15.8 \%)$ & $\begin{array}{c}13 \\
(68.4 \%)\end{array}$ \\
\hline for entertainment & $1(5.3 \%)$ & - & $2(10.5 \%)$ & $7(36.8 \%)$ & $4(21.1 \%)$ & $5(26.3 \%)$ \\
\hline $\begin{array}{l}\text { interest in music or } \\
\text { singing itself }\end{array}$ & - & - & $1(5.3 \%)$ & $4(21.1 \%)$ & $6(31.6 \%)$ & $8(42.1 \%)$ \\
\hline $\begin{array}{l}\text { to create atmosphere } \\
\text { in social situations }\end{array}$ & - & - & $3(15.7 \%)$ & $2(10.5 \%)$ & $7(36.8 \%)$ & $7(36.8 \%)$ \\
\hline $\begin{array}{l}\text { to enhance positive } \\
\text { moods }\end{array}$ & - & - & & $3(15.7 \%)$ & $5(26.3 \%)$ & $\begin{array}{c}11 \\
(57.9 \%) \\
\end{array}$ \\
\hline $\begin{array}{l}\text { to forget about } \\
\text { present }\end{array}$ & $2(10.5 \%)$ & - & $5(26.3 \%)$ & $4(21.1 \%)$ & $4(21.1 \%)$ & $4(21.1 \%)$ \\
\hline $\begin{array}{l}\text { to relax and calm } \\
\text { down }\end{array}$ & - & - & $2(10.5 \%)$ & $4(21.1 \%)$ & $4(21.1 \%)$ & $9(47.4 \%)$ \\
\hline $\begin{array}{l}\text { to reduce feeling of } \\
\text { loneliness }\end{array}$ & $1(5.3 \%)$ & - & 2 & $6(31.6 \%)$ & $4(21.1 \%)$ & $6(31.6 \%)$ \\
\hline $\begin{array}{l}\text { to feel akin with } \\
\text { others }\end{array}$ & - & - & $1(5.3 \%)$ & $5(26.3 \%)$ & $8(42.1 \%)$ & $5(26.3 \%)$ \\
\hline $\begin{array}{l}\text { to gain control of } \\
\text { sounds }\end{array}$ & - & - & $2(10.5 \%)$ & $5(26.3 \%)$ & $4(21.1 \%)$ & $8(42.1 \%)$ \\
\hline to learn new skills & - & - & $1(5.3 \%)$ & $5(26.3 \%)$ & $6(31.6 \%)$ & $7(36.8 \%)$ \\
\hline $\begin{array}{l}\text { to strengthen self- } \\
\text { esteem }\end{array}$ & & & $1(5.3 \%)$ & $4(21.1 \%)$ & $5(26.3 \%)$ & $9(47.4 \%)$ \\
\hline
\end{tabular}

When answering whether they joined the tele-based music program for entertainment, a total of 7 (36.8\%) participants responded that it was somewhat true, followed by 5 (26.3\%) responses that stated very true; 4 (21.1\%) responded true, 2 (10.5\%) responded somewhat very untrue, and $1(5.3 \%)$ responded very untrue.

It could be asked whether the participants were interested in music so that the music program appeared to be more appealing to them with this as a reason for some who decided to join it. Based on the responses, 8 (42.1\%) responded very true to the statement, followed by 6 $(31.6 \%)$ who responded true, 4 (21.1\%) responded somewhat true, and 1 (5.3\%) responded somewhat untrue.

When answering whether they joined the program because of wanting to create an atmosphere for socializing, $7(36.8 \%)$ responded very true to the statement, another 7 $(36.8 \%)$ responded true, $3(15.7 \%)$ responded somewhat untrue, and 2 (10.5\%) responded somewhat true.

Moreover, there were 11 responses (57.9\%) who stated very true to the statement that they joined the tele-base music program to enhance positive mood, followed by 5 (26.3\%) who 
responded true, and 3 (15.8\%) who responded somewhat true. When answering whether they joined the program to forget about the present, the majority $(\mathrm{N}=5,26.3 \%)$ responded that it was somewhat untrue, followed by $4(21.1 \%)$ responses that stated somewhat true, 4 $(21.1 \%)$ true and $4(21.1 \%)$ very true, whilst $2(10.5 \%)$ responded very untrue.

Table 2 also showed the responses of the participants to whether they joined the music program to relax and clam down, $9(47.4 \%)$ responded very true, $4(21.1 \%)$ responded true, 4 (21.1\%) responded somewhat true, and 2 (10.5\%) responded somewhat untrue; When answering whether it was to reduce the feeling of loneliness. 6 (31.6\%) responded very true, another $6(31.6 \%)$ responded somewhat true, $4(21.1 \%)$ responded true, $2(10.5 \%)$ responded somewhat untrue, and 1 (5.3\%) responded very untrue; When answering whether they joined the program to want to feel akin with others, $8(42.1 \%)$ responded that it was true, followed by $5(26.3 \%)$ who responded very true, $5(26.3 \%)$ who responded somewhat true, and 1 $(5.3 \%)$ responded somewhat untrue.

When trying to find out whether the participants joined the program to gain control of sounds, $8(42.1 \%)$ responded very true, $5(26.3 \%)$ responded somewhat true, $4(21.1 \%)$ responded true, and $2(10.5 \%)$ responded somewhat untrue; and when answering whether it was to learn new skill, 7 (36.8\%) responded very true, 6 (31.6\%) responded true, 6 (31.6\%) responded somewhat true, 1 (5.3\%) responded somewhat untrue; Lastly, when answering whether it was to strengthen self-esteem, $9(47.4 \%)$ responded very true, followed by 5 $(26.3 \%)$ who responded true, $4(21.1 \%)$ responded somewhat true, and 1 (5.3\%) responded somewhat untrue. 
INTERNATIONAL JOURNAL OF ACADEMIC RESEARCH IN BUSINESS AND SOCIAL SCIENCES Vol. 11, No. 11, 2021, E-ISSN: 2222-6990 ๑ 2021 HRMARS

Table 3: Descriptive statistics of Frequency of Emotional Reactions After the Tele-based Music Program

\begin{tabular}{lcccc}
\hline Variables & \multicolumn{4}{c}{$\mathbf{N}(\%)$} \\
\hline Happy & never & seldom & often & always \\
enjoying & - & - & $8(42.1 \%)$ & $11(57.9 \%)$ \\
Calm & - & - & $8(42.1 \%)$ & $11(57.9 \%)$ \\
interested & - & - & $13(68.4 \%)$ & $6(31.6 \%)$ \\
motivated & - & - & $11(57.9 \%)$ & $8(42.1 \%)$ \\
Relaxed & - & $2(10.5 \%)$ & $9(47.7 \%)$ & $8(42.1 \%)$ \\
hopeful & - & - & $12(63.2 \%)$ & $7(36.8 \%)$ \\
Loving & $1(5.3 \%)$ & $12(63.2 \%)$ & $6(31.6 \%)$ & - \\
Uplifted & $1(5.3 \%)$ & $1(5.3 \%)$ & $11(57.9 \%)$ & $6(31.6 \%)$ \\
relieved & $1(5.3 \%)$ & $4(21.1 \%)$ & $8(42.1 \%)$ & $6(31.6 \%)$ \\
nostalgic & $1(5.3 \%)$ & $4(21.1 \%)$ & $9(47.4 \%)$ & $5(26.3 \%)$ \\
Longing & - & $4(21.1 \%)$ & $12(63.2 \%)$ & $3(15.8 \%)$ \\
reminisces & $1(5.3 \%)$ & $4(21.1 \%)$ & $12(63.2 \%)$ & $2(10.5 \%)$ \\
Proud & $5(26.3 \%)$ & $5(26.3 \%)$ & $6(31.6 \%)$ & $3(15.8 \%)$ \\
honoured & $1(5.3 \%)$ & $5(26.3 \%)$ & $8(42.1 \%)$ & $5(26.3 \%)$ \\
Tense & $5(26.3 \%)$ & $10(52.6 \%)$ & $4(21.14 \%)$ & - \\
disappointed & $12(63.2 \%)$ & $6(31.6 \%)$ & $1(5.3 \%)$ & - \\
Bored & $8(42.1 \%)$ & $4(21.1 \%)$ & $7(36.8 \%)$ & - \\
Jealous & $13(68.4 \%)$ & $5(26.3 \%)$ & $1(5.3 \%)$ & - \\
Afraid & $10(52.6 \%)$ & $7(36.8 \%)$ & $2(10.5 \%)$ & - \\
Anxious & $8(42.1 \%)$ & $4(21.1 \%)$ & $5(26.3 \%)$ & $2(10.5 \%)$ \\
Sad & $9(47.7 \%)$ & $9(47.7 \%)$ & - & $1(5.3 \%)$ \\
\hline & & & $8(42.1 \%)$ & \\
\end{tabular}

Table 3 presents the findings of the frequency of emotional reactions derived through the tele-based music program. The positive emotional measures showed a trend towards higher frequency, this could be summarized as: 11 (57.9\%) always happy, 8 (42.1\%) often happy; 11 (57.9\%) always enjoying, 8 (42.1\%) often enjoying; 6 (31.6\%) always calm, 13 (68.4\%) often calm; 8 (42.1\%) always interested, 11 (57.9\%) often interested; 8 (42.1\%) always motivated, 9 (47.7\%) often motivated, 2 (10.5\%) seldom motivated; 7 (36.8\%) always relaxed, 12 (63.2\%) often relaxed; 7 (36.8\%) always hopeful, 8 (42.1\%) often hopeful, 4 (21.1\%) seldom hopeful; $6(31.6 \%)$ often loving, 12 (63.2\%) seldom loving, 1 (5.3\%), never loving; 6 (31.6\%) always uplifted, 11 (57.9\%) often uplifted, 1 (5.3\%) seldom uplifted, 1 (5.3\%) never uplifted; 6 (31.6\%) always relieved, 8 (42.1\%) often relieved, 4 (21.1\%) seldom relieved, 1 (5.3\%) never relieved.

For the mixed emotional reactions, the findings could be summarized as follow: 5 (26.3\%) always nostalgic, 9 (47.4\%) often nostalgic, 4 (21.1\%) seldom nostalgic, 1 (5.3\%) never nostalgic; 3 (15.8\%) always longing, 12 (63.2\%) longing, 4 (21.1\%) seldom longing; 2 (10.5\%) always reminisces, 12 (63.2\%) often reminisces, 4 (21.1\%) seldom reminisces, 1 (5.3\%) never reminisces; 3 (15.8\%) always proud, 6 (31.6\%) often proud, 5 (26.3\%) seldom proud, 5 (26.3\%) never proud; 5 (26.3\%) always honoured, 8 (42.1\%) often honoured, 5 (26.3\%) seldom honoured, 1 (5.3\%) never honoured; The negative emotional reactions were reported as follow: 4 (21.14\%) often tensed, 10 (52.6\%) seldom tensed, 5 (26.3\%) never tensed; 1 (5.3\%) often disappointed, 6 (31.6\%) seldom disappointed, 12 (63.2\%) never disappointed; 7 (36.8\%) 
often bored, 4 (21.1\%) seldom bored, 8 (42.1\%) never bored; 1 (5.3\%) often jealous, 5 (26.3\%) seldom jealous, 13 (68.4\%) never jealous, 2 (10.5\%) often afraid, 7 (36.8\%) seldom afraid, 10 (52.6\%) never afraid; 2 (10.5\%) always anxious, 5 (26.3\%) often anxious, 4 (21.1\%) seldom anxious, 8 (42.1\%) never anxious, 1 (5.3\%) always sad, 9 (47.7\%) seldom sad and $9(47.7 \%)$ never sad.

In general, for the positive emotional reactions, the responses from the participants showed some initial trends towards saying often and always positive; mixed responses for the mixed emotional reactions, and for the negative emotional reactions, the responses also showed some initial trends towards seldom and never. However, this study did not intend to compare the difference in the emotional reactions by category. It was also noted that the small sample size from this exploratory study did not yield an outcome that could be generalized. However, it gave some preliminary findings to clarify the situation for better policy decision-making when formulating an online intervention program.

The questionnaire consisted of an open-ended question at the end, aiming to further explore the participants' general view on the experience of the tele-based music program. The responses were grouped, coded and themed as shown in the table 4 below. 
Table 4: Themes Describing Feedbacks of the Tele-based Music Program

\begin{tabular}{|c|c|c|c|c|}
\hline Themes & Codes & Responses & $\begin{array}{c}\text { Reference } \\
\text { by } \\
\text { participants }\end{array}$ & $\begin{array}{c}\text { Total } \\
\text { reference } \\
\text { in themes }\end{array}$ \\
\hline \multirow[t]{3}{*}{$\begin{array}{l}\text { Reception of the } \\
\text { tele-based music } \\
\text { program }\end{array}$} & $\begin{array}{l}\text { Like/ Enjoyed } \\
\text { the music } \\
\text { program }\end{array}$ & $\begin{array}{l}\text { - Like Singing } \\
\text { - Enjoyed the } \\
\text { sessions } \\
\text { - Encouraging } \\
\text { - Uplifting } \\
\text { - Interesting } \\
\text { - Motivated } \\
\text { - Inspired }\end{array}$ & $\begin{array}{l}1 \\
2 \\
1 \\
1 \\
1 \\
1 \\
1\end{array}$ & 8 \\
\hline & $\begin{array}{l}\text { Benefits of the } \\
\text { program to } \\
\text { overcome } \\
\text { problems } \\
\text { caused by PD }\end{array}$ & $\begin{array}{l}\text { - Singing can } \\
\text { improve vocal } \\
\text { quality. } \\
\text { - Singing keeps spirit } \\
\text { up. } \\
\text { - Singing makes me } \\
\text { forget about PD } \\
\text { - Singing helps me to } \\
\text { stay positive. } \\
\text { - Belief music can } \\
\text { help to improve } \\
\text { physical and mental } \\
\text { problems caused by } \\
\text { PD. }\end{array}$ & $\begin{array}{l}1 \\
1 \\
1 \\
1 \\
1\end{array}$ & 5 \\
\hline & $\begin{array}{l}\text { General } \\
\text { feedback to the } \\
\text { tele-based } \\
\text { music program }\end{array}$ & $\begin{array}{l}\text { - Feeling appreciated } \\
\text { for the opportunity } \\
\text { - Requesting for } \\
\text { more sessions } \\
\text { - A very good } \\
\text { program }\end{array}$ & $\begin{array}{l}2 \\
1 \\
2\end{array}$ & 5 \\
\hline Comments & $\begin{array}{l}\text { Comments for } \\
\text { Improvements }\end{array}$ & $\begin{array}{l}\text { - 2-hours is too long } \\
\text { - Need improvement } \\
\text { on audio quality. }\end{array}$ & $\begin{array}{l}1 \\
3\end{array}$ & 4 \\
\hline
\end{tabular}

The Open-ended question at the end of the questionnaire revealed interesting findings on the general reception of the tele-based music program. The responses could be categorized into two main groups: the general reception of the program and the comments for improvements.

From the responses of the general reception category, the participants reported that they found the tele-based music program enjoyable, uplifting, interesting, encouraging, inspiring and felt motivated. This further strengthened their beliefs that they believed music had the potential to help with keeping their spirits up and to help them stay positive as music made 
them forget about the disease. They also believed that music intervention had the potential to create a positive impact on their physical and mental states, including to improve their vocal problems. The participants thus made a request for more of these programs in the future.

The open-ended question summarized some interesting comments on how to improve a telebased music program. The biggest issue or the most mentioned proposal was to improve on the audio and sound qualities, as music intervention relied on the clarity of sound. Hence this is of utmost importance when the tele-based music program is introduced. This also further implied that the aid of audio technology is crucial by enhancing the audio equipment or by improving one's knowledge and skill on music-technology. Another participant also responded on the total length of the tele-based music program where a 2-hours session was too long for the PwPs as that could be very tiring for them.

\section{Discussion \& Recommendations for Future Research}

The coronavirus disease 2019 (COVID-19) pandemic has brought unprecedented changes in the management of PD care and quality of life of PwP in many countries (Elbeddini et al., 2020). However, there are no studies at present assessing the current status of people with Parkinson's Disease in Malaysia in response to the ongoing COVID-19 pandemic. Hence, the main objective of this exploratory study was to investigate the effects of a tele-based music program on the psychosocial wellbeing of people with Parkinson's Disease during the period of the Movement Control Order brought about by the Covid-19 pandemic. The results gleaned from this preliminary study have yielded several noteworthy insights for further examination and consideration in future research.

The current research reveals that while many hospitals have to prioritize and focus solely on treating COVID-19 patients, people with chronic illnesses such as Parkinson's Disease who are already experiencing social isolation and loneliness due to the physical limitations imposed by the disease, found their situation worsening. Participation in the tele-based music program provided the study participants with opportunities for social engagements that helped to mitigate against levels of social distancing which caused isolation and loneliness amplified by the pandemic. The tele-based music program provided a "safe space" for the nineteen participants to regularly connect with their peers and engage in positive social interactions through the music program. Participants in this study reported experiencing feelings of happiness, enjoyment, calmness, interest, motivation relaxation and hopefulness and not much feelings of tension, disappointment and boredom.

As regular hospital appointments and visits to the local Parkinson's Disease association to participate in activities were suspended due to the recurrent Movement Control Order, more recent research conducted during the Covid-19 pandemic found that individuals with chronic diseases such as PD are prone to higher levels of anxiety caused by the additional psychological pressure of receiving insufficient and inadequate medical consultation as most hospitals in Malaysia focused primarily on treating COVID-19 patients. A research showed that this resulted in worsening the levels of sleep quality and mental health (Xia et al., 2020). Future studies may want to explore the correlation between participation in the tele-based music program and the level of sleep quality, as well as the correlation between participation in the tele-based music program and overall levels of mental health to determine the strength 
of the relationship in helping to mitigate the two known Covid-19 related comorbidities, specifically in individuals with PD (Shalash et al., 2020).

The results of this study indicated that the provision of a home-based online tele music program provided much needed psychosocial support which enabled participants in the study who were home-bound an outlet to share their health concerns and anxieties, in a manner that enabled family caregivers and professionals who were present with opportunities to intervene and provide support (Elbeddini et al., 2020). Informally, the tele-based music program functioned as a therapeutic support group and psychological safety net for people with Parkinson's Disease who participated in the study. Based on the preliminary findings of this study, future research may want to extend the duration of the tele-based music program and study the long-term effects of it. This could help determine if the positive effects observed in this initial study were constant and the long-term benefits of the program on people with Parkinson's Disease's overall quality of life and levels of anxiety, while the pandemic persists.

Existing research suggests that there are gender differences in PwPs' HrQoL. Thus. additional recommendations for future studies which stem from this initial study may want to include the observation of differences in gender responses in lieu of developing future permutations of the tele-based music program. Such findings would be useful in helping to develop telebased music programs that cater more adequately to the differing gender needs in people with Parkinson's Disease. Moreover, differences between gender responses to coping in the midst of the Covid-19 pandemic could be revealed via the tele-based music program if the latter was expanded into a music and counselling-based program.

Based on the participants' responses, it appeared that the tele-based music program was positively received by the caregivers who were present during the sessions. The receptivity of the caregivers seemed to suggest the possibility of incorporating caregivers into future permutations of the program to ascertain if the tele-based music program could potentially help caregivers, and if so in what ways. This implied the need for an additional questionnaire to be developed specifically targeting caregivers participating in the study to determine if the tele-based music program could also potentially benefit Parkinson's Disease caregivers based on their self-report. On that note, future studies might want to explore how the tele-based music program could be mobilized to increase opportunities for family caregivers and people with Parkinson's Disease's bonding and positive interactions.

\section{Conclusion}

This paper reported findings from an exploratory study on the reception of an online telebased music program. As physical distancing was mandated during the COVID-19 pandemic, an immediate alternative plan for therapeutic intervention and innovative care was much needed for people with chronic diseases such as Parkinson's Disease. Whilst there is a paucity of research that looked into tele-based music intervention, this exploratory study aimed to explore the feasibility to develop an online tele-based musical care system.

The results of this study showed the reasons why the participants decided to take part in this program, and the preliminary findings also revealed some positive perceptions towards the tele-based music program. 
A full-fledged tele-based music intervention program should be further developed, and more in-depth research should follow. These should include RCT research with bigger sample sizes and more observations on the gender differences. In-depth qualitative research should also be carried out to better understand the phenomena as these data could give clearer guidelines for better policy making.

\section{References}

Aarsland, D., Larsen, J. P., Karlsen, K., Lim, N. G., \& Tandberg, E. (1999). Mental symptoms in Parkinson's disease are important contributors to caregiver distress. International Journal of Geriatric Psychiatry, 14(10), 866-874. https://doi.org/10.1002/(SICI)10991166(199910)14:10<866::AID-GPS38>3.0.CO;2-Z

Alves, G., Forsaa, E. B., Pedersen, K. F., Dreetz Gjerstad, M., \& Larsen, J. P. (2008). Epidemiology of Parkinson's disease. Journal of Neurology, 255(SUPPL. 5), 18-32. https://doi.org/10.1007/s00415-008-5004-3

Baker, F., \& Krout, R. (2009). Songwriting via Skype. British Journal of Music Therapy, 23(2), 3-14. https://doi.org/10.1177/135945750902300202

Balzer-Geldsetzer, M., Klotsche, J., Reetz, K., Spottke, A., Storch, A., Baudrexel, S., Mollenhauer, B., Berg, D., Liepelt, I., Kassubek, J., Kalbe, E., Wittchen, H. U., Dodel, R., \& Riedel, O. (2018). Quality of life in a German cohort of Parkinson's patients assessed with three different measures. Journal of Neurology, 265(11), 2713-2722. https://doi.org/10.1007/s00415-018-9047-9

Beck, R. J., Cesario, T. C., \& Yousefi, A. (2000). Choral Singing , Performance Perception , and Immune System Changes in Salivary Immunoglobulin A and Cortisol Author ( $s$ ): R. J . Beck, T . C . Cesario, A . Yousefi and H . Enamoto Published by : University of California Press Stable URL : http://www. Music Perception: An Interdisciplinary Journal, 18(1), 87106.

Boland, D. F., \& Stacy, M. (2012). The economic and quality of life burden associated with Parkinson's disease: a focus on symptoms. The American Journal of Managed Care, 18(september), S168-75. http://www.ncbi.nlm.nih.gov/pubmed/23039865

Branchi, I., D’Andrea, I., Armida, M., Cassano, T., Pezzola, A., Potenza, R. L., Morgese, M. G., Popoli, P., \& Alleva, E. (2008). Nonmotor symptoms in Parkinson's disease: Investigating early-phase onset of behavioral dysfunction in the 6-hydroxydopamine-lesioned rat model. Journal of Neuroscience Research, 86(9), 2050-2061. https://doi.org/10.1002/jnr.21642

Buczak-Stec, E. W., König, H. H., \& Hajek, A. (2018). Impact of incident Parkinson's disease on satisfaction with life. Frontiers in Neurology, 9(JUL). https://doi.org/10.3389/fneur.2018.00589

Calne, S. M., Lidstone, S. C., \& Kumar, A. (2008). Psychosocial issues in young-onset Parkinson's disease: Current research and challenges. Parkinsonism and Related Disorders, 14(2), 143-150. https://doi.org/10.1016/j.parkreldis.2007.07.012

Cerri, S., Mus, L., \& Blandini, F. (2019). Parkinson's Disease in Women and Men: What's the Difference? Journal of Parkinson's Disease, 9(3), 501-515. https://doi.org/10.3233/JPD191683

Chaudhuri, K. R., Healy, D. G., \& Schapira, A. H. V. (2006). Non-motor symptoms of Parkinson's disease: diagnosis and management. Lancet Neurol, 5(3), 235-245. https://doi.org/10.1016/s1474-4422(06)70373-8

Chung, T. H., Deane, K. H. O., Ghazi-Noori, S., Rickards, H., \& Clarke, C. E. (2003). Systematic 
review of antidepressant therapies in Parkinson's disease. Parkinsonism and Related Disorders, 10(2), 59-65. https://doi.org/10.1016/S1353-8020(03)00108-1

Clift, S., \& Hancox, G. (2010). The significance of choral singing for sustaining psychological wellbeing: findings from a survey of choristers in England, Australia and Germany. Music Performance Research, 3, 79-96. https://doi.org/Article

Clift, S., Hancox, G., Morrison, I., Hess, B., Kreutz, G., \& Stewart, D. (2010). Choral singing and psychological wellbeing: Quantitative and qualitative findings from English choirs in a cross-national survey. Journal of Applied Arts \& Health, 1(1), 19-34. https://doi.org/10.1386/jaah.1.1.19/1

De Lau, L. M. L., \& Breteler, M. M. B. (2006). Epidemiology of parkinson's disease. Lancet Neurol, 5, 525-535. https://doi.org/10.1016/S1016-3190(10)60044-4

Dyduch, A., \& Załuska, M. (2014). Depression in Parkinson's disease: the effectiveness and risk of pharmacotherapy. Clinical review. Psychogeriatrics: The Official Journal of the Japanese Psychogeriatric Society, 1-7. https://doi.org/10.1111/psyg.12078

Elbeddini, A., To, A., Tayefehchamani, Y., \& Wen, C. (2020). Potential impact and challenges associated with Parkinson's disease patient care amidst the COVID-19 global pandemic. Journal of Clinical Movement Disorders, 7(1), 1-7. https://doi.org/10.1186/s40734-02000089-4

Fogg-Rogers, L., Buetow, S., Talmage, A., McCann, C. M., Leao, S. H. S., Tippett, L., Leung, J., McPherson, K. M., \& Purdy, S. C. (2015). Choral singing therapy following stroke or Parkinson's disease: an exploration of participants' experiences. Disability and Rehabilitation, 8288(November), 1-11.

https://doi.org/10.3109/09638288.2015.1068875

Grape, C., Sandgren, M., Hansson, L.-O., Ericson, M., \& Theorell, T. (2003). Does singing promote well-being?: An empirical study of professional and amateur singers during a singing lesson. Integrative Physiological and Behavioral Science, 38(1), 65-74. https://doi.org/10.1007/BF02734261

Hughes, A. J., Daniel, S. E., Kilford, L., \& Lees, A. J. (1992). Accuracy of clinical diagnosis of idiopathic Parkinson's disease : a clinico-pathological study of 100 cases. 181-184. https://doi.org/10.1136/jnnp.55.3.181

Jankovic, J. (2008). Parkinson's disease: clinical features and diagnosis. Journal of Neurology, Neurosurgery \& Psychiatry, 79(4), 368-376. https://doi.org/10.1136/jnnp.2007.131045

Juslin, P. N., \& Sloboda, J. A. (2010). Handbook of music and emotion. In Theory, Research, Applications (p. 975). OUP Oxford. https://doi.org/10.1093/acprof

Lightstone, A. J., Bailey, S. K., \& Voros, P. (2015). Collaborative music therapy via remote video technology to reduce a veteran's symptoms of severe, chronic PTSD. Arts and Health, 7(2), 123-136. https://doi.org/10.1080/17533015.2015.1019895

Lim, S.-Y., Fox, S. H., \& Lang, A. E. (2009). Overview of the extranigral aspects of Parkinson disease. Archives of Neurology, 66(2), 167-172. https://doi.org/10.1001/archneurol.2008.561

Lim, S.-Y., Puvanarajah, S., Lee, M. K., Chee, K. Y., Viswanathan, S., Tan, A. H., Chong, K. T., \& Azrin, K. (2012). 2012 Consensus Guidelines for the Treatment of Parkinson's Disease.

Massano, J., \& Bhatia, K. P. (2012). Clinical Approach to Parkinson's Disease : Cold Spring Harbor Laboratory Press, 1-16.

Meireles, J., \& Massano, J. (2012). Cognitive impairment and dementia in Parkinson's disease: Clinical features, diagnosis, and management. Frontiers in Neurology, MAY(May), 1-16. https://doi.org/10.3389/fneur.2012.00088 
Ophey, A., Eggers, C., Dano, R., Timmermann, L., \& Kalbe, E. (2018). Health-Related Quality of Life Subdomains in Patients with Parkinson's Disease: The Role of Gender. Parkinson's Disease, 2018. https://doi.org/10.1155/2018/6532320

Pacchetti, C., Mancini, F., Aglieri, R., Fundarò, C., Martignoni, E., \& Nappi, G. (2000). Active music therapy in Parkinson's disease: an integrative method for motor and emotional rehabilitation. Psychosomatic Medicine, 62, 386-393.

https://doi.org/10.1097/00006842-200005000-00012

Politis, M., Wu, K., Molloy, S., Bain, P. G., Chaudhuri, K. R., \& Piccini, P. (2010). Parkinson's disease symptoms: The patient's perspective. Movement Disorders, 25(11), 1646-1651. https://doi.org/10.1002/mds.23135

Pont-Sunyer, C., Hotter, A., Gaig, C., Seppi, K., Compta, Y., Katzenschlager, R., Mas, N., Hofeneder, D., Brücke, T., Bayés, A., Wenzel, K., Infante, J., Zach, H., Pirker, W., Posada, I. J., Álvarez, R., Ispierto, L., De Fàbregues, O., Callén, A., ... Tolosa, E. (2015). The onset of nonmotor symptoms in parkinson's disease (the onset pd study). Movement Disorders, 30(2), 229-237. https://doi.org/10.1002/mds.26077

Prasad, S., Holla, V., Neeraja, K., Surisetti, B., Kamble, N., Yadav, R., \& Pal, P. (2020). Impact of Prolonged Lockdown due to COVID-19 in Patients with Parkinson's Disease. Neurology India, 68(4), 792-795. https://doi.org/10.4103/0028-3886.293472

Prediger, R. D. S., Matheus, F. C., Schwarzbold, M. L., Lima, M. M. S., \& Vital, M. A. B. F. (2012). Anxiety in Parkinson's disease: A critical review of experimental and clinical studies. Neuropharmacology, 62(1), 115-124.

https://doi.org/10.1016/j.neuropharm.2011.08.039

Pringsheim, T., Jette, N., Frolkis, A., \& Steeves, T. D. L. (2014). The prevalence of Parkinson's disease: A systematic review and meta-analysis. Movement Disorders, 29(13), 15831590. https://doi.org/10.1002/mds.25945

Rahman, S., Griffin, H. J., Quinn, N. P., \& Jahanshahi, M. (2008). Quality of life in Parkinson's disease: The relative importance of the symptoms. Movement Disorders, 23(10), 14281434. https://doi.org/10.1002/mds.21667

Rutten, S., Ghielen, I., Vriend, C., Hoogendoorn, A. W., Berendse, H. W., Leentjens, A. F. G., van der Werf, Y. D., Smit, J. H., \& van den Heuvel, O. A. (2014). Anxiety in Parkinson's disease: Symptom dimensions and overlap with depression and autonomic failure. Parkinsonism and Related Disorders. https://doi.org/10.1016/j.parkreldis.2014.11.019

Schrag, A. (2006). Quality of life and depression in Parkinson's disease. Journal of the Neurological Sciences, 248(1-2), 151-157. https://doi.org/10.1016/j.jns.2006.05.030

Schrag, A., Jahanshahi, M., \& Quinn, N. (2000). How does Parkinson's disease affect quality of life? A comparison with quality of life in the general population. Movement Disorders, 15(6), 1112-1118. https://doi.org/10.1002/1531-8257(200011)15:6<1112::AIDMDS1008>3.0.CO;2-A

Schulz, G. M., \& Grant, M. K. (2000). Effects of speech therapy and pharmacologic and surgical treatments on voice and speech in Parkinson's disease: a review of the literature. Journal of Communication Disorders, 33, 59-88. https://doi.org/10.1016/S0021-9924(99)000258

Shalash, A., Roushdy, T., Essam, M., Fathy, M., Dawood, N. L., Abushady, E. M., Elrassas, H., Helmi, A., \& Hamid, E. (2020). Mental Health, Physical Activity, and Quality of Life in Parkinson's Disease During COVID-19 Pandemic. Movement Disorders, 35(7), 10971099. https://doi.org/10.1002/mds.28134

Shulman, L. M., Taback, R. L., Rabinstein, A. A., \& Weiner, W. J. (2002). Non-recognition of 
depression and other non-motor symptoms in Parkinson's disease. Parkinsonism \& Related Disorders, 8(3), 193-197. https://doi.org/10.1016/S1353-8020(01)00015-3

Vaudreuil, R., Langston, D. G., Magee, W. L., Betts, D., Kass, S., \& Levy, C. (2020). Implementing music therapy through telehealth: considerations for military populations. Disability and Rehabilitation: Assistive Technology, 0(0), 1-10.

https://doi.org/10.1080/17483107.2020.1775312

Vella-Burrows, T., Hancox, G., \& Sidney De Haan Research Centre for Arts and Health. (2012). Singing and people with Parkinson 's. 24.

http://www.canterbury.ac.uk/Research/Centres/SDHR/Documents/Singingandpeoplew ithParkinsons.pdf

Wee, N., Kandiah, N., Acharyya, S., Chander, R. J., Ng, A., Au, W. L., \& Tan, L. C. S. (2016). Depression and anxiety are co-morbid but dissociable in mild Parkinson's disease: A prospective longitudinal study of patterns and predictors. Parkinsonism \& Related Disorders, 23, 50-56. https://doi.org/10.1016/j.parkreldis.2015.12.001

Xia, Y., Kou, L., Zhang, G., Han, C., Hu, J., Wan, F., Yin, S., Sun, Y., Wu, J., Li, Y., Zhang, Z., Huang, J., Xiong, N., \& Wang, T. (2020). Investigation on sleep and mental health of patients with Parkinson's disease during the Coronavirus disease 2019 pandemic. Sleep Medicine, 75, 428-433. https://doi.org/10.1016/j.sleep.2020.09.011 